\title{
MEK-2, a Caenorhabditis elegans MAP kinase kinase, functions in Ras-mediated vulval induction and other developmental events
}

\author{
Yan Wu, ${ }^{1}$ Min Han, ${ }^{1}$ and Kun-Liang Guan ${ }^{2,3}$ \\ ${ }^{1}$ Department of Molecular, Cellular, and Developmental Biology, University of Colorado at Boulder, Boulder, Colorado \\ 80309 USA $^{2}$ Department of Biological Chemistry and the Institute of Gerontology, University of Michigan Medical School, \\ Ann Arbor, Michigan 48109 USA
}

\begin{abstract}
Activated Ras initiates a cascade of sequential phosphorylation events, including the protein kinases Raf, MEK, and MAP kinase. The Let-60 Ras-mediated signal transduction pathway controls vulval induction in Caenorhabditis elegans. Both Lin-45 Raf and Sur-1 MAP kinase have been determined to be essential factors during vulval induction; however, the $C$. elegans mek gene has not been identified. In this paper, we have cloned a $C$. elegans mek gene, mek-2, and demonstrated that the MEK-2 protein possesses the biochemical properties of MAP kinase kinases: The C. elegans MEK-2 protein can phosphorylate and activate a human MAP kinase (ERK1), and MEK-2 itself can be phosphorylated and activated by immunoprecipitated mammalian Raf. The mek-2 gene plays a key role in the let-60 ras-mediated vulval induction pathway, as loss-of-function mutations in the gene (ku114 and h294) significantly reduce the signal transmitted through Ras. mek-2(ku114) completely suppressed the Multivulva (Muv) phenotype of a hyperactive let-60 ras mutation, and animals homozygous for mek-2(ku114) also displayed a partial larval lethal phenotype. Animals homozygous for mek-2(h294) exhibited a highly penetrant sterile and Vulvaless phenotype. Microinjection of a gain-of-function mek-2 mutation resulted in Muv and other mutant phenotypes, whereas microinjection of a dominant-negative mutation not only suppressed the Muv phenotype of an activated let-60 ras mutation but also caused an egg-laying defective phenotype in otherwise wild type animals. Our results demonstrate that mek-2 acts between lin-45 raf and sur-1/mpk-1 in a signal transduction pathway used in the control of vulval differentiation and other developmental events.
\end{abstract}

[Key Words: mek-2; MAP kinase kinase; vulval induction; C. elegans; signal transduction; ras]

Received January 4, 1995; revised version accepted February 14, 1995.

A variety of extracellular proliferation and differentiation factors induce protein kinase cascades that result in phosphorylation and regulation of numerous cellular proteins (Crews and Erikson 1993; Davis 1994). Receptors for many of these growth and differentiation factors are receptor tyrosine kinases (RTKs), which transmit signals through the GTP-binding protein Ras (McCormick 1993). Activated Ras initiates a cascade of sequential phosphorylation events in which the serine-threonine kinase Raf phosphorylates and activates MEK (also known as MAP kinase kinase) (Dent et al. 1992; Howe et al. 1992; Kyriakis et al. 1992). MEK, a dual specificity kinase, phosphorylates threonine and tyrosine residues of MAP kinase (also known as ERK), thus leading to the activation of MAP kinase (Boulton et al. 1990; Crews and Erikson 1992). The MAP kinase cascade is highly

${ }^{3}$ Corresponding author. conserved in eukaryotic organisms including yeast, Drosophila, and mammals (Blumer and Johnson 1994). The activated MAP kinases phosphorylate and regulate many cellular proteins including receptors (Northwood et al. 1991), phospholipase (Lin et al. 1993), other kinases (Sturgill et al. 1988; Stokoe et al. 1992), and nuclear transcription factors (Gille et al. 1992; Hill et al. 1993; Marais et al. 1993). The mammalian MEK displays a high substrate selectivity toward MAP kinase in vitro (Seger et al. 1992a) once it is activated by Raf-mediated phosphorylation of two conserved serine residues, Ser-218 and Ser-222 (Alessi et al. 1994; Zheng and Guan 1994). It has been demonstrated in human MEK1 that substitutions of both Ser-218 and Ser-222 by glutamate or aspartate residues result in a constitutively active form of the protein that is sufficient for NIH-3T3 cell transformation and PCl2 cell differentiation (Cowley et al. 1994; Mansour et al. 1994). In contrast, changing these serine residues to alanines results in an interfering mutant 
MEK that could block serum-induced DNA synthesis and revert ras-or src-transformed cells (Cowley et al. 1994), demonstrating that MEK activation is necessary for cell growth.

Developmental, genetic, and molecular studies in Caenorhabditis elegans have shown that multiple intercellular signals are essential for vulval differentiation (Horvitz and Sternberg 1991). During vulval induction, the gonadal anchor cell induces three of the six vulval precursor cells to generate vulval tissue (Fig. 1). The other three cells generate nonspecific epidermis. Several genes necessary for vulval induction encode proteins homologous to factors that act in mammalian RTK/Rasmediated signal transduction. The lin-3 gene product, an epidermal growth factor (EGF)-like molecule, is the inductive signal from the anchor cell that induces vulval differentiation (Hill and Sternberg 1992); the let-23 gene encodes a receptor tyrosine kinase that is likely to be the receptor for Lin-3 (Aroian et al. 1990); the sem-5 gene, encoding a protein with Src homology domains $\mathrm{SH} 2$ and $\mathrm{SH} 3$, has been proposed to act between the RTK and Ras (Clark et al. 1992). Activation of Let-60 Ras initiates a kinase cascade including Lin-45, a Raf serine-threonine kinase (Han et al. 1993), and Sur-1, a MAP kinase (Lackner et al. 1994; Wu and Han 1994).

Vulval induction has provided an excellent model system to study the Ras-mediated signaling pathway. Al-

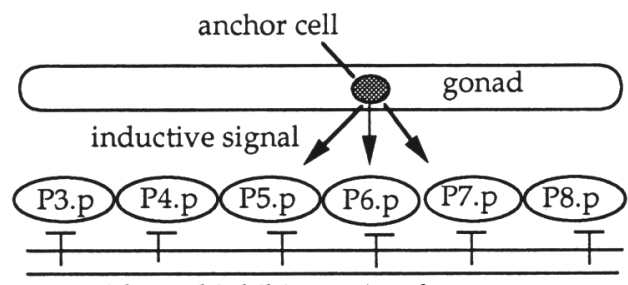

epidermal inhibitory signal
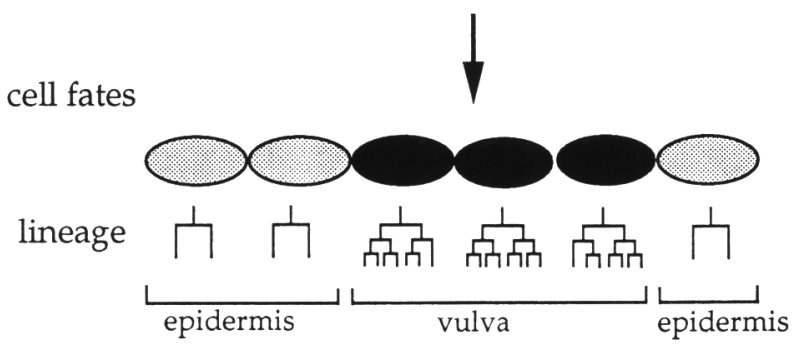

Figure 1. A model for vulval cell fate specification in wild-type C. elegans. The six multipotent vulval precursor cells /VPCs, P3.p-P8.p, depicted as open ovals) are located just ventral to the gonad. An inhibitory signal from the surrounding epidermis prevents vulval differentiation (Herman and Hedgecock 1990). However, an inductive signal from the anchor cell in the somatic gonad induces the nearby VPCs to adopt vulval cell fates (solid ovals) (Horvitz and Sternberg 1991; Hill and Sternberg 1992). These induced cells divide three rounds, and the progeny generate vulval tissue. The other three precursor cells divide only once and then fuse with the surrounding syncytial epidermis (shaded ovals). The wild-type lineages of each VPC are depicted (Sulston and Horvitz 1977). The precursor P3.p does not divide in $50 \%$ of wild-type hermaphrodites. though both Lin-45 Raf and Sur-1 MAP kinase have been determined to be essential factors during $C$. elegans vulval differentiation (Han et al. 1993; Lackner et al. 1994; $\mathrm{Wu}$ and Han 1994), the function of the MEK protein has not been identified in C. elegans. To further understand the biological function of MAP kinase cascade in a developmental organism, we have cloned and characterized a C. elegans mek gene, mek-2. We show here that the mek-2 gene encodes a protein that is structurally and biochemically similar to mammalian MEK proteins. Through genetic analysis of loss-of-function mutations, and ectopically expressed dominant mutations, we determined that the mek-2 gene plays an essential role in the $1 e t-60$ ras-mediated vulval signal transduction pathway. The pleiotropic defects associated with various mek-2 mutations indicate that this gene is involved in multiple developmental events in C. elegans.

\section{Results}

The C. elegans mek-2 gene encodes a protein that is homologous to mammalian MAP kinase kinases

To identify C. elegans MEK homologs, degenerate oligonucleotides corresponding to the conserved amino acid sequences in the MEK family were used to amplify sequences by polymerase chain reactions (PCR) from a cDNA library (see Material and methods). Sequence analysis of amplified DNA revealed two MEK homologs, mek-1 and mek-2. MEK-2 has high amino acid sequence identity with the mammalian MEK, whereas MEK-1 is more distantly related to mammalian MEK (P. Kayne et al., pers. comm.; K.-L. Guan, unpubl.).

The PCR product corresponding to mek-2 was used to screen a mixed stage cDNA library (Stratagene). Four positive clones were isolated after screening 300,000 plaques. All four cDNA clones encoded the same protein based on their restriction maps and their $5^{\prime}$ sequences. The longest cDNA clone was completely sequenced and had an open reading frame of 385 amino acid residues, which shares a significant sequence identity to mammalian MEK. The $3^{\prime}$ end of the cDNA sequences was determined by identifying the poly(A) tails of the cDNA clones. However, the translational start codon ATG was missing in the longest cDNA clone isolated. To identify the $5^{\prime}$ end of the cDNA, two primers, one complementary to the vector and the other complementary to the mek-2 cDNA, were used to amplify sequences by PCR from the cDNA library. A $0.2-\mathrm{kb}$ fragment was isolated and sequenced that contained a putative initiation ATG codon and 11 nucleotides corresponding to the SL1 trans-splicing leader sequence that is frequently found at the $5^{\prime}$ end of $C$. elegans transcripts (Krause and Hirsh 1987). Thus, we conclude that the full-length mek-2 cDNA encodes a primary translation product containing 387 amino acids (Fig. 2). As shown in Figure 3, 54\% of the amino acids in the mek-2 gene product are identical to human MEK1 (Seger et al. 1992b; Zheng and Guan 1993 ), and $55 \%$ of them are identical to the Drosophila MEK homolog Dsor-1 (Tsuda et al. 1993). All of the con- 


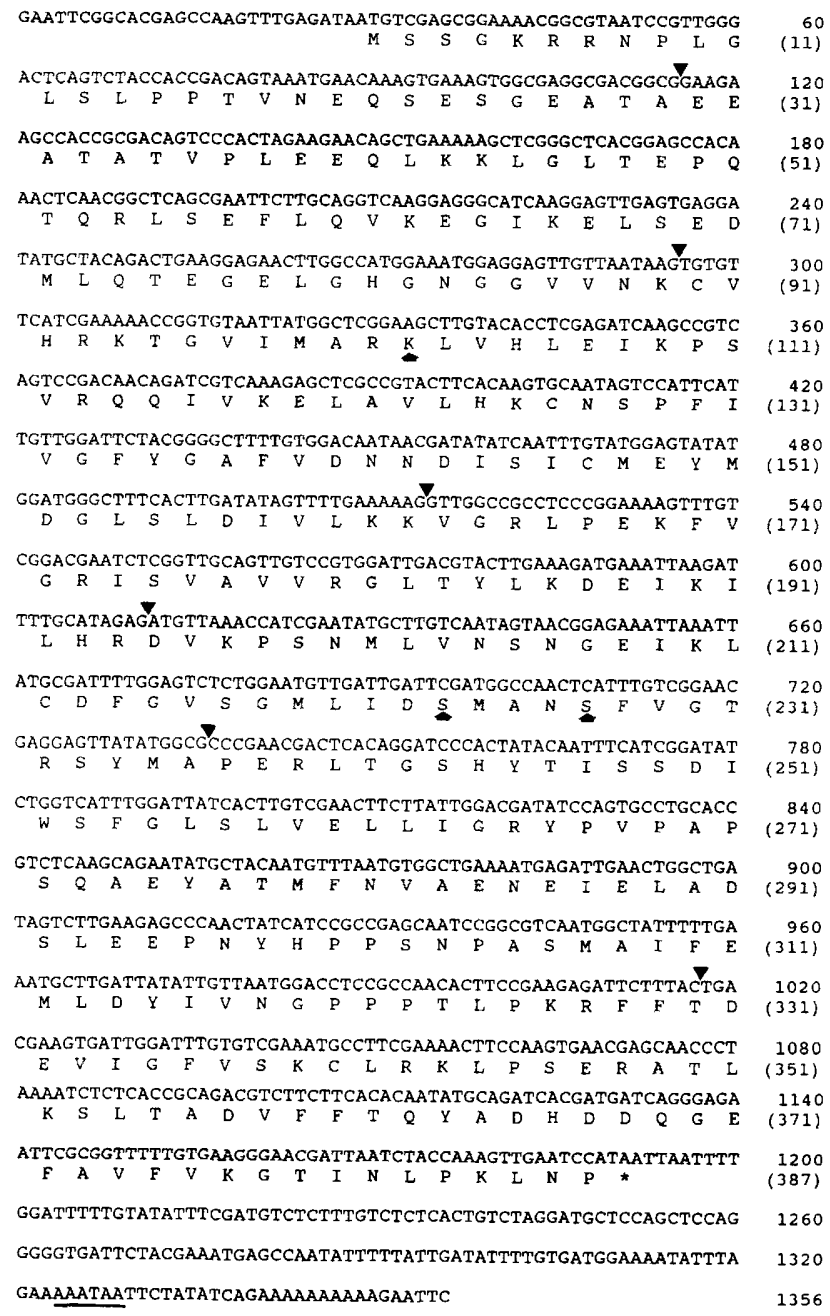

Figure 2. Nucleotide sequence of mek-2 cDNA and deduced amino acid sequence. The predicted amino acid sequence (in single-letter code) is shown underneath the nucleotide sequence. Numbers at right indicate the positions of nucleotides or amino acids (in parenthesis). ( $\mathbf{V}$ ) The positions of introns as determined by genomic DNA sequencing. The putative polyadenylation signal sequences (AAATAA), 11 nucleotides upstream of the poly|A|, are underlined. The catalytic essential lysine residue 102 and the activation phosphorylation sites Ser223 and Ser-227 are indicated by short, thick upward arrows. The longest cDNA isolated from the cDNA library starts at the third codon. DNA sequence of the 5 ' leader, the first two codons, and intron 1 were obtained from PCR products /see Materials and methods for details).

served structural motifs, including the two phosphorylation target sites, S218 and S222 of human MEK1, are also conserved in C. elegans MEK-2 (Figs. 2 and 3).

We used the mek-2 cDNA as a probe to hybridize a $C$. elegans yeast artificial chromosome (YAC) library (a gift from A. Coulson of Sanger Center, Cambridge, UK) and determined that a YAC clone, Y71F9, contained at least part of the mek-2 gene. Further Southern analysis showed that another overlapping YAC clone, Y54E10, contained the whole mek-2 cDNA sequence /data not shown). These data position mek-2 on the left arm of chromosome I.

To determine the gene structure of mek-2, a genomic DNA library from a yeast strain containing Y54E10 was constructed using $\lambda$ Ziplox as the vector. This library, which had a complexity of $5 \times 10^{6}$ independent clones, was screened using mek-2 cDNA as a probe. Genomic clones were isolated and the exon-intron boundaries were sequenced. The $C$. elegans mek-2 gene contains seven exons and six introns (Fig. 4).

\section{$M E K-2$ protein functions biochemically between Raf and $M A P$ kinase}

Studies from mammalian cells have demonstrated that MEK functions between Raf and MAP kinase (Ahn et al. 1992; Crews and Erikson 1993; Davis 1994; Guan 1994). To determine whether the cloned C. elegans MEK-2 behaves biochemically as a MAP kinase kinase, MEK-2 was expressed in Escherichia coli as a glutathione $S$-transferase (GST)-MEK-2 fusion protein. The recombinant fusion protein, GST-MEK-2 was purified by glutathione affinity chromatography to near homogeneity as analyzed by SDS-PAGE. The GST-MEK- 2 fusion protein was mostly insoluble under normal inducible conditions $\left(200 \mu \mathrm{M}\right.$ IPTG at $\left.37^{\circ} \mathrm{C}\right)$. However, when the E. coli culture was being induced with a lower concentration of IPTG $(20 \mu \mathrm{M})$ at room temperature, most of the expressed fusion proteins were found to be soluble. Approximately $1 \mathrm{mg}$ of GST-MEK- 2 fusion protein was obtained from 1 liter of bacterial culture. The purified GST-MEK-2 fusion protein could phosphorylate and activate purified human ERK1 in vitro (Fig. 5A,B). Activation of human ERK1 showed a linear correlation with the concentration of purified GST-MEK-2 fusion protein used in the assay (Fig. 5B). In the control experiments, the GST protein itself could not phosphorylate and activate human ERK1, nor was the GST-MEK-2 fusion protein able to phosphorylate myelin basic protein (MBP) directly. Phosphoamino acid analysis of human ERKl phosphorylated by GST-MEK-2 fusion protein showed that both tyrosine and threonine residues of ERK1 were phosphorylated (data not shown). These results suggest that the $C$. elegans MEK-2 protein is a dual specific kinase that activates MAP kinase. It is worth noting that the C. elegans MEK-2 has a basal kinase activity significantly lower than human MEK1 in the ERK activation assay.

We have also determined that the C. elegans MEK-2 can be phosphorylated and activated in vitro by mammalian Raf (Fig. 5C,D). Anti-Raf antibody was used to immunoprecipitate activated Raf from EGF-stimulated Swiss 3T3 cells. Immunoprecipitated Raf was then tested for activation of GST-MEK-2 in vitro. Activation of GST-MEK-2 was determined by a coupled kinase assay in which the GST-MEK-2 activity was measured by the activation of ERK1. In the presence of activated Raf and GST-MEK-2 fusion protein, the kinase activity of human ERK1 increased dramatically as compared with the ERKl kinase activity in the presence of only the GST-MEK-2 fusion protein or the ERK1 basal activity 


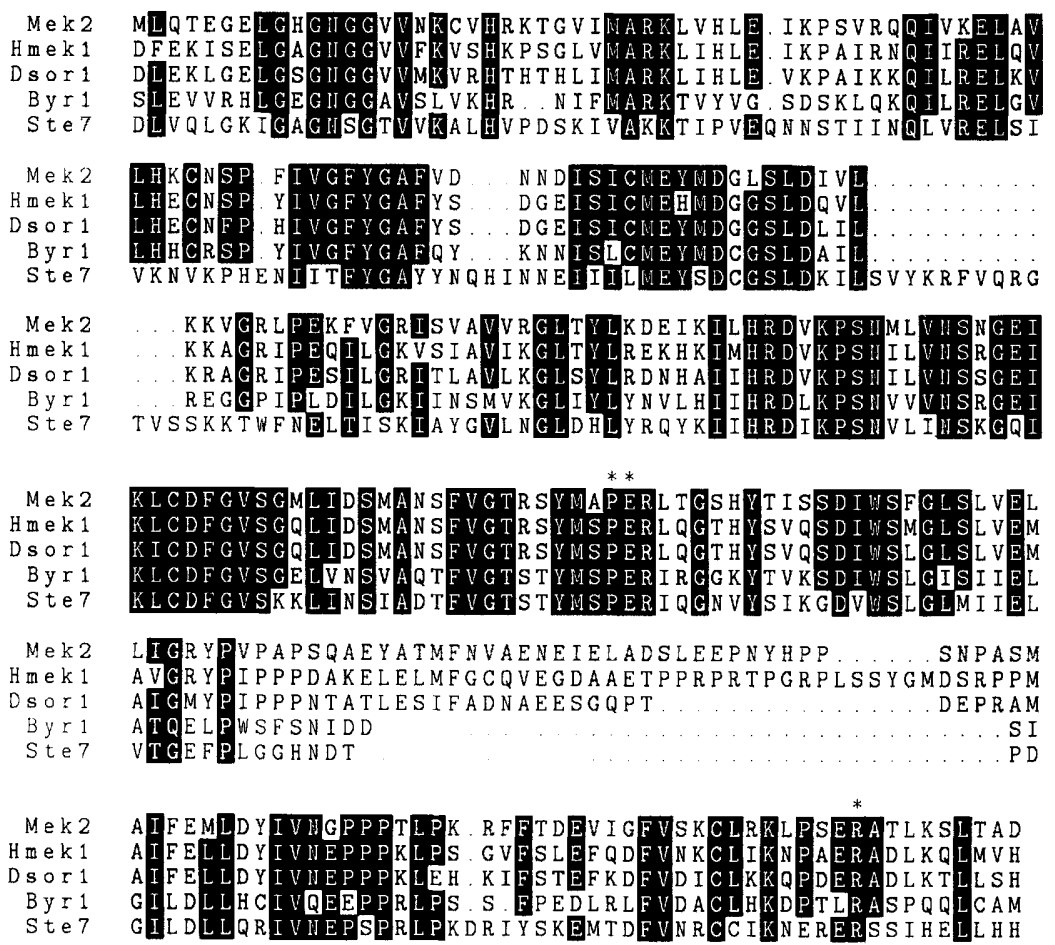

Figure 3. Amino acid sequence comparison of the predicted MEK-2 product with members of the MEK family. The deduced amino acid sequence of MEK-2 (residues 72-357) was aligned with human MEK1 (Hmekl, residues 67-358) (Seger et al. 1992b; Zheng and Guan 1993), Drosophila Dsorl (residues 83-358) (Tsuda et al. 1993), Schizosaccharomyces pombe Byrl (residues 65-317) (Nadin-Davis and Nasim 1988), and Saccharomyces cerevisiae Ste7 (residues 190463) (Teague et al. 1986) using the PILEUP program of the Wisconsin Genetic Computation Group. Gaps (denoted by dots) were introduced for maximum alignment. Highly conserved residues (four out of five) are highlighted. Pro-237 and Glu-238, which are mutated in the mek2(ku114) and (h294) alleles, respectively, and Arg-348, which should form a salt bridge with Glu-238, are indicated by asterisks (*).
(Fig. 5C,D). In control experiments, neither immunoprecipitated Raf in the absence of the GST-MEK-2 fusion protein nor precipitation with nonspecific serum was able to activate human ERK1. These data suggest that the $C$. elegans MEK-2 can be phosphorylated and activated by Raf kinase. In conclusion, the C. elegans MEK-2 functions in vitro as a MAP kinase kinase between Raf and MAP kinase.

ku1 14 and h294 are mutant alleles of mek-2 that affect vulval differentiation

In a genetic screen to identify additional factors acting downstream of Let-60 Ras, we have isolated $>60$ mutations that suppress the Multivulval (Muv) phenotype of an activated let-60 ras mutation, let-60(n1046 gf) (Wu and Han 1994; M. Han, unpubl.). One of the recessive extragenic suppressor mutations, ku114, maps to the left arm of chromosome $I$ in a region that corresponds to the position of mek-2 on the physical map (Material and methods). ku114 completely suppresses the Muv phenotype of the let-60(n1046) ras mutation: 0\% Muv animals were found in ku114; let-60(n1046) homozygotes, whereas animals homozygous for the let-60 mutation alone are $\sim 95 \%$ Muv (Table 1). Forty animals homozygous for both ku114 and let-60(n1046) and 50 animals homozygous for ku114 alone were examined for vulval induction by Normarski microscopy; all of them displayed a wild-type vulval lineage (Table 1; Fig. 6A).

ku114 mapped close to another mutation, h294, which was isolated in A. Rose's laboratory (McKim 1990). h294 homozygous mutant animals were sterile (McKim 1990)

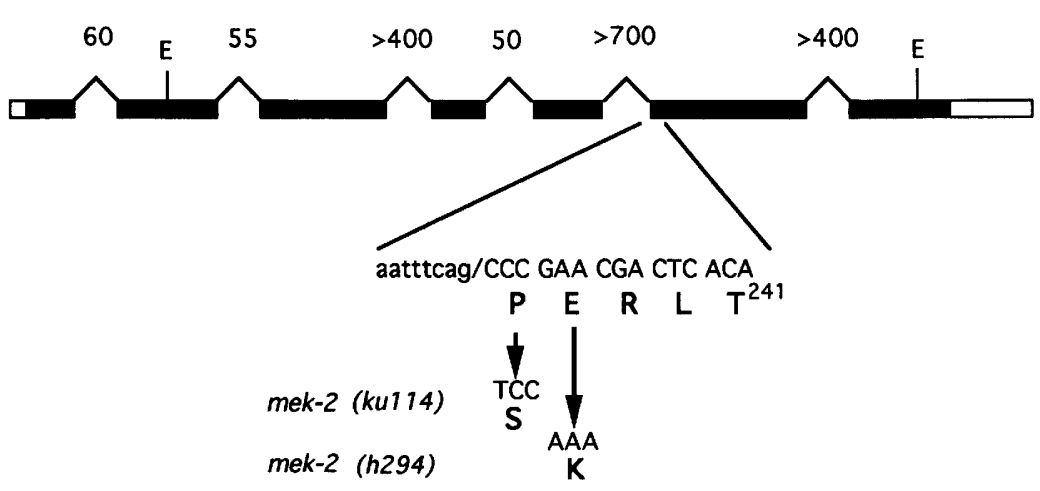

Figure 4. Genomic structure of the mek-2 gene and molecular lesions of mek-2(ku114) and mek2(h294). The seven exons of mek-2 are represented by bars. The solid bars indicate the coding region of exons, the open bars denote the $5^{\prime}$ and $3^{\prime}$ untranslated sequences. Sizes of the six introns are indicated by the numbers above each intron. The EcoRI restriction sites $(\mathrm{E})$ are also indicated by a vertical line. Both mutant alleles of mek-2 contain a nucleotide substitution in exon 6 . Sequences at the junction of intron 5 and exon 6 are shown in detail. Nucleotides of intron and exon are shown in lowercase and uppercase, respectively. The position of Thr-241 is indicated by $\left(\mathrm{T}^{241}\right)$. Pro- 237 is substituted by a serine because of a nucleotide $\mathrm{C} \rightarrow \mathrm{T}$ change in mek-2(ku114). Similarly, Glu238 is replaced by a lysine because a nucleotide $\mathrm{G} \rightarrow \mathrm{A}$ alteration in mek-2(h294). 
Wu et al.
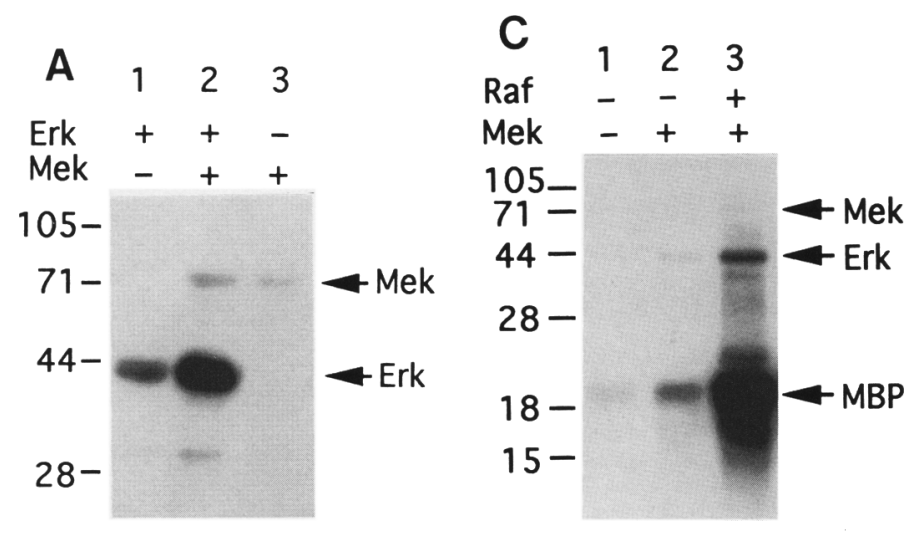

B
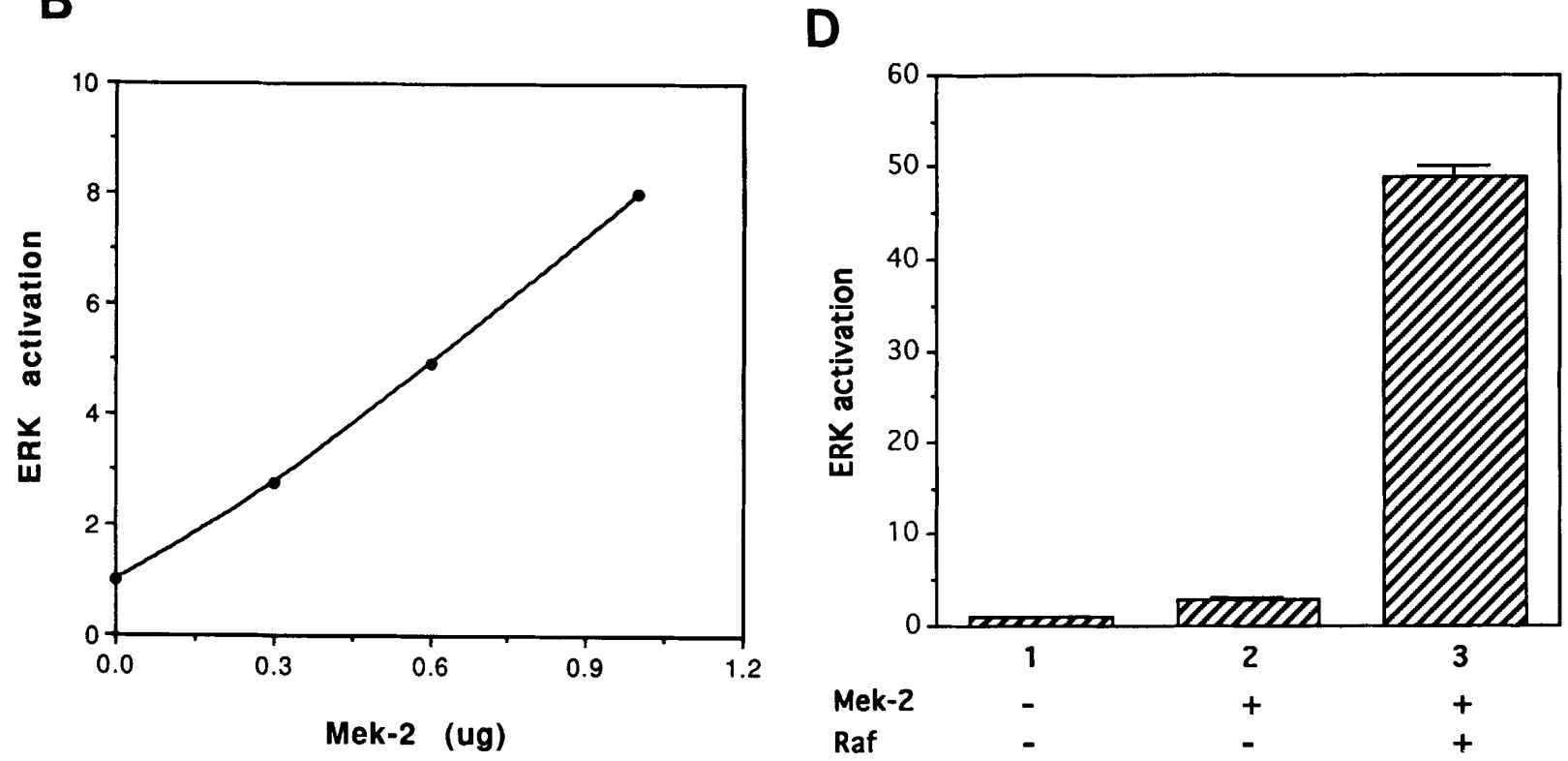

Figure 5. (A) Phosphorylation of ERK1 by recombinant MEK-2. Purified recombinant human ERK1 and GST-MEK-2 were phosphorylated in vitro in the presence of $\left[\gamma^{-32} \mathrm{P} \mid\right.$ ATP. (Lane 1) Autophosphorylation of ERK1 $(1 \mu \mathrm{g})$; (lane 2) phosphorylation of ERK1 (1 $\mu \mathrm{g}$ ) in the presence of GST-MEK-2 $(2 \mu \mathrm{g})$; (lane 3) autophosphorylation of GST-MEK-2 $(2 \mu \mathrm{g})$. The positions of molecular weight standards are indicated at left. Arrows denote the positions of ERK1 (Erk) and GST-MEK-2 (Mek). (B) In vitro activation of ERK1 by GST-MEK-2. ERK1 $(0.3 \mu \mathrm{g})$ was activated by various amounts of GST-MEK-2. Activated ERK1 was then assayed using myelin basic protein (MBP) as a substrate. The activity of ERK was quantitated by scintillation counting of ${ }^{32} \mathrm{P}$ incorporation into MBP. Value of the untreated ERKl was normalized to 1 . Fold of ERK activation (y-axis) is linearly correlated to the amount of GST-MEK-2 ( $x$-axis) used in the experiment. $(C)$ Activation of GST-MEK-2 by Raf as analyzed by SDS-PAGE. Activation of GST-MEK- 2 was determined by a coupled kinase activation assay in which the GST-MEK-2 activity was measured by the activation of ERK1. (Lane 1$)$ ERK1)(0.3 $\mu \mathrm{g})$ alone; (lane 2) basal activity of GST-MEK-2 (0.3 $\mu \mathrm{g}$ ERK1 and $0.3 \mu \mathrm{g}$ GST-MEK-2); (lane 3) activation of GST-MEK-2 by the immunoprecipitated Raf $(0.3 \mu \mathrm{g}$ ERK1 and $0.3 \mu \mathrm{g}$ Raf-activated GST-MEK-2). GST-MEK-2 was first activated by immunoprecipitated Raf. The Raf kinase complexed with protein A-agarose was removed by centrifugation, and the activated GST-MEK- 2 was then used in the ERK activation assay. Positions of GST-MEK-2 (Mek), ERK1 (Erk), and MBP are indicated. (D) Activation of GST-MEK-2 by Raf. Quantitation of the kinase assay was determined by scintillation counting of ${ }^{32} \mathrm{P}$ incorporation into MBP. Data are from two independent experiments. Conditions for lanes 1,2 and 3 are identical to those in $C$.

and defined a gene that is likely to act in vulval signaling pathway (E. Lambie, pers. comm.). We examined 30 h294 homozygous worms under Normarski microscopy and observed that h294 has a fully penetrant Vulvaless (Vul) phenotype: All the vulval precursor cells divided once and then fused with the surrounding syncycial hypodermis (Table 1; Fig. 6B). Thus, h294 defines a gene absolutely required for vulval differentiation.

Because $h 294$ and ku114 map to the same chromo- some region as the cloned mek-2 gene, we examined the possibility that the two mutations were alleles of mek-2. We first determined that ku114 and h294 fail to complement each other for the egg-laying defective (Egl) phenotype (data not shown), suggesting that they are two mutations of the same locus. Second, we tested the ability of mek-2 to rescue these mutations. Because we were unable to clone the promoter region of the mek-2 gene, we microinjected the mutant lines with a construct in 
Table 1. Effect of ku114 and h294 on vulval differentiation

\begin{tabular}{lccc}
\hline & $\begin{array}{l}\text { Percent } \\
\text { vulval } \\
\text { induction } \\
(n)^{\mathrm{a}}\end{array}$ & $\begin{array}{l}\text { Percent } \\
\text { Egl }(n)^{\mathrm{b}}\end{array}$ & $\begin{array}{l}\text { Percent } \\
\text { larval } \\
\text { lethal } \\
(n)^{\mathrm{c}}\end{array}$ \\
\hline Genotype & $100(50)$ & $1(343)$ & $8(398)$ \\
ku114 & $100(40)$ & $28(398)$ & $0(400)$ \\
hu114; let-60(n1046) & $0(30)$ & N.A. & N.A. \\
\hline
\end{tabular}

(n) Number of worms examined.

aPercent of vulval induction as examined by a Normarski DIC microscopy.

bercent of animals defective in egg-laying.

'Percent of progeny that died as larvae.

(N.A.) Not available.

which the mek-2 cDNA was fused to a heat shock promoter, hspl6-41 (Stringham et al. 1992). The HS-mek-2 plasmid was injected into ku114; let-60(n1046) at $\sim 20 \mu \mathrm{g} / \mathrm{ml}$ with a rol-6(d) DNA as a dominant marker for transformation (Mello et al. 1991). Because ku114 completely suppressed the Muv phenotype of let60(n1046 gf), rescue should cause the reappearance of the Muv phenotype in a ku114; let-60(n1046 gf) double mutant strain. Among 22 independent transgenic lines tested, the Muv phenotype ranged from $40 \%$ to $100 \%$, with an average of $\sim 73 \%$. A control strain of ku114; let-60(n1046 gf) displayed $0 \%$ Muv, whereas a strain of let-60(n1046 gf) alone displayed $\sim 95 \%$ Muv. These data showed that ectopic expression of mek-2 rescued the mutant phenotype of ku114.

To further confirm that ku114 and h294 are mutations in the mek-2 gene, we sequenced mek-2 in the mutants and identified the molecular lesions. The coding region and intron/exon boundaries of both mutant DNA were amplified by PCR using multiple sets of oligonucleotide primers of mek-2, and the PCR products were sequenced directly. ku114 has a single nucleotide change from $\mathrm{C}$ to $\mathrm{T}$ in codon 237, which results in the substitution of a serine for proline 237 (Fig. 4). h294 also has a single nucleotide change from $\mathrm{G}$ to $\mathrm{A}$ in codon 238 , which results in the substitution of a lysine for glutamic acid 238 (Fig. 4). Both the proline and glutamic acid residues are highly conserved in the protein kinase family. Substitution of either amino acid residue is likely to cause a significant change in protein conformation and, therefore, decrease the kinase activity (see Discussion). The molecular lesions of the mek-2 mutations are also consistent with the genetic analysis that both ku114 and h294 are likely to be loss-of-function mutations. Thus, we conclude that ku114 and h294 are two mutant alleles of the mek-2 gene.

Because the mutations of mek-2 completely suppressed the Muv phenotype of an activated let-60 ras mutation, mek-2 most likely acts downstream of let- 60 ras in the vulva induction pathway. The MAP kinase cascades are highly conserved among different organisms. In mammalian systems it has been shown that MEK acts between Raf kinase and MAP kinase. Because
MEK-2 resembles MEK, both structurally and functionally, in mammals, we propose that mek-2 acts downstream of 1 in- 45 but upstream of sur-1 in the C. elegans vulval signaling pathway (Fig. 7).

\section{$M E K-2$ functions in multiple developmental processes in $\mathrm{C}$. elegans}

Both ku114 and h294 display mutant phenotypes in addition to defective vulval differentiation. For example, animals homozygous for mek-2(h294) are $100 \%$ sterile (this study; McKim 1990). The effects of mek-2 loss-offunction alleles on germ-line differentiation have been studied in detail by (Church et al. 1995). A similar sterile phenotype is observed in a severe loss-of-function mutation of the sur-1 MAP kinase gene, oz140 (Church et al. 1995; T. Schedl; M.R. Lackner and S.K. Kim; both pers. comm.), suggesting that both mek-2 and sur-1 play an important role in a signaling pathway that controls $C$. elegans germ-line differentiation. Although animals homozygous for mek-2(ku114) displayed no obvious Egl phenotype, mek-2(ku114); let-60(n1046) double mutants displayed an Egl phenotype, whereas the mutants showed wild-type vulval differentiation (Table 1). These results are consistent with our previous observations that sur-1(ku1); let-60(n1046) mutant animals also displayed an Egl phenotype despite wild-type vulval differentiation (Wu and Han 1994).

Animals homozygous for mek-2(ku114) displayed $\sim 8 \%$ larval lethality, whereas the mek-2(ku114); let60(n1046) double mutant animals displayed $0 \%$ larval lethality (Table 1). The dying mek-2(ku114) homozygous animals arrested at different larval stages. The earliest arrest appears at the Ll larval stage. A similar percentage of larval lethality was observed in sur-1(ku1) or sur-1(ku1); let-60(n1046) homozygous animals (Wu and Han 1994). These data suggest that both mek-2 and sur-1 play important roles in early development. The mek2(ku114) mutation appears also to suppress the mutant phenotype in the male tails of the let-60(n1046 gf) animals (Chamberlin and Sternberg 1993), as the male mating defect was suppressed in the mek-2(ku114); let60(n1046) double mutants (data not shown). These results suggest that mek-2 and sur-1 may act together in multiple aspects of $C$. elegans development.

Microinjection of multiple copies of a mek-2 cDNA construct does not cause a dominant mutant phenotype

To test whether microinjection of multiple copies of mek-2 was sufficient to generate a Muv phenotype, constructs that contain the wild-type mek-2 cDNA under the control of the heat shock promoters hsp16-2 or hsp16-41 (Stringham et al. 1992) were injected into a wild-type strain (N2) with rol-6(d) DNA as a marker for transformation (Mello et al. 1991). We failed to observe Muv animals in 33 independent transgenic lines after heat shock at different developmental stages (Table 2).

Previously, we have shown that injection of high copy numbers of the sur-1 gene did not cause a dominant phe- 
Figure 6. Photomicrographs showing different mutant phenotypes associated with different mutant forms of mek-2. $(A, B)$ Animals are at the early L4 larval stage and magnified $590 \times ;(C-F)$ animals are at the adult stage and magnified $236 \times$. (A) The vulva induction of ku114; let-60(n1046) homozygous animals is wild type. The arrow indicates the wild-type vulva. $(B)$ Animals homozygous for h294 display a Vul phenotype. All of the vulva precursor cells only divide once and then fuse with the surrounding epidermis. The bars show that P5.p, P6.p, and P7.p only divide once. $(C)$ Ectopic expression of mek-2(S223ES227D) causes a Muv phenotype. The black arrow points to the wild-type vulva; the white arrows point to the two pseudovulvae. $(D) \mathrm{Ec}$ topic expression of mek-2(S223ES227D) causes hermaphrodite tail abnormality. $(E)$ Activated let-60 mutation, let-60(n1046), causes a Muv phenotype. The black arrow points to the wild-type vulva, while the white arrows point to the two pseudovulvae. $(F)$ Ectopic expression of mek2(S223AS227A) suppresses the Muv phenotype of the activated let-60 mutation, let60(n1046). The white arrow points to a larva hatched inside the hermaphrodite.
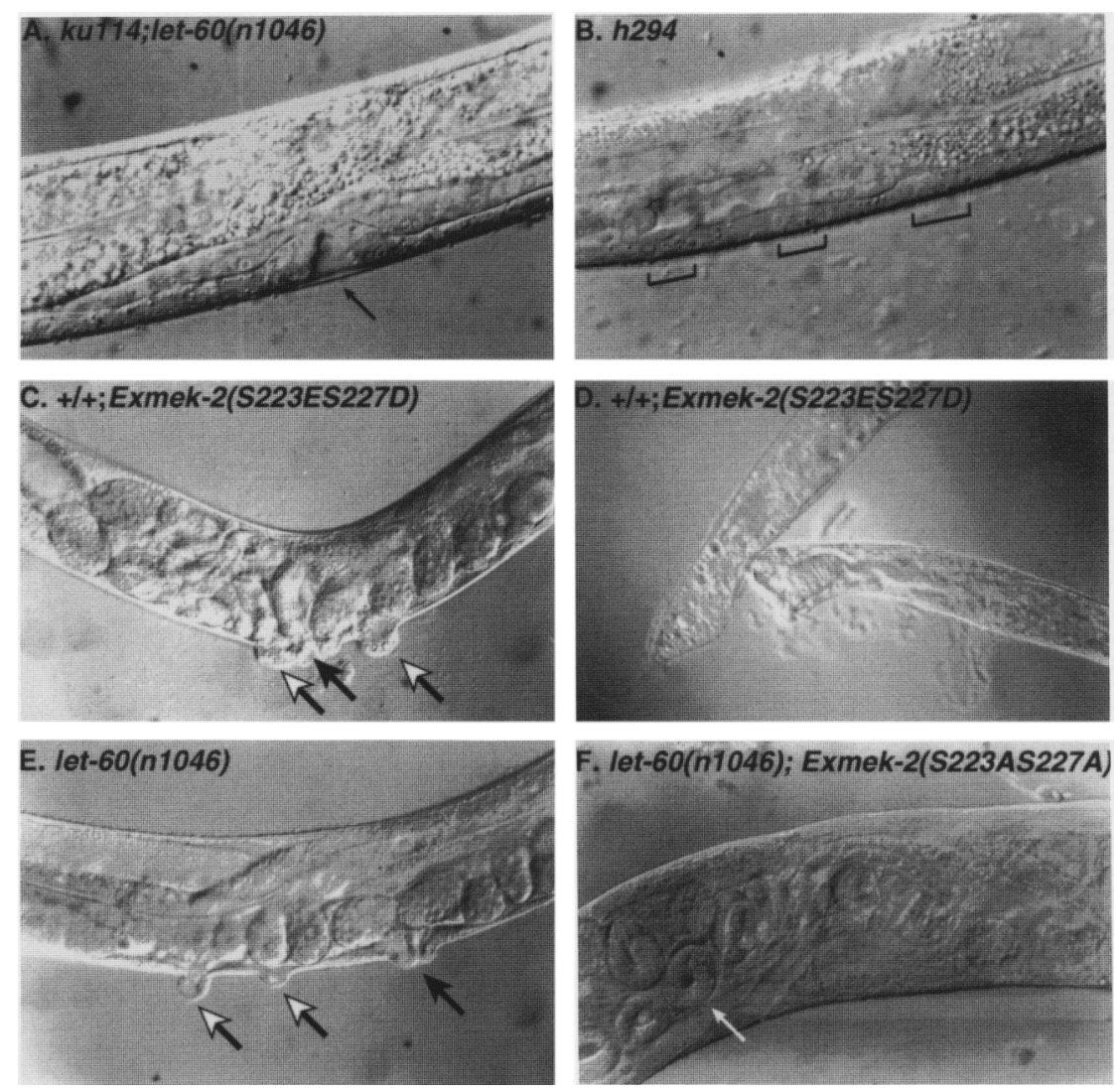

notype (Wu and Han 1994). We have now extended this study by showing that ectopic expression of the sur-1 cDNA under the control of the heat shock promoters, hsp16-2 or hsp16-41, did not cause a dominant Muv phenotype (Table 2). These sur-1 fusion constructs were clearly functional, as they were able to rescue the mutant phenotype of sur-1(ku1) in 17 independent transgenic lines (data not shown). Because the mek-2 and sur-1 genes may act together in a signaling pathway that controls different aspects of worm development, multiple copies of mek-2 and sur-1 under the control of the heat shock promoters were also coinjected to test any synergistic effects. None of the 44 transgenic lines tested displayed a Muv phenotype after heat shock at different developmental stages (Table 2).

In conclusion, microinjection of multiple copies of mek-2, sur-1, or mek-2 and sur-1 together in C. elegans, unlike microinjection of multiple copy numbers of the let-60 ras gene (Han and Sternberg 1990), did not cause a Muv phenotype, suggesting that the quantities of these enzymes are unlikely to be limiting factors in the signaling pathway. Our data agree with previous observations that overexpression of wild-type MEK or MAP kinase in mammalian cell lines caused no transforming phenotype (Seger et al. 1992b; Cowley et al. 1994). These results are consistent with the notion that the regulation of the MEK and MAP kinase activity is at the level of protein activity.

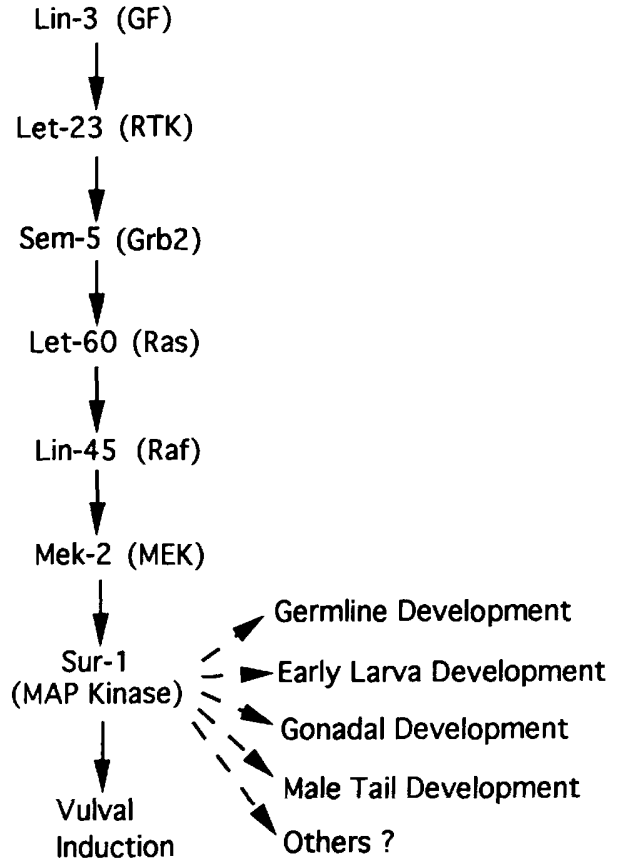

Figure 7. The Let-60 Ras mediated MAP kinase pathway in vulval induction and other development events. Gene products of mammalian homologs are indicated in parentheses. GF and RTK denote for growth factor like molecule and receptor tyrosine kinase, respectively. 
Table 2. Phenotypic analysis of microinjection of multiple copies of mek-2 or sur-1

\begin{tabular}{lcc}
\hline Contructs $^{\mathrm{a}}$ & $\begin{array}{l}\text { Lines with } \\
\operatorname{Muv}(n)^{\mathrm{b}}\end{array}$ & \multicolumn{1}{c}{$\begin{array}{c}\text { Percent } \\
\text { Muv }(\mathrm{n})^{\mathrm{c}}\end{array}$} \\
\hline HS-mek-2|+) & $0 / 33$ & $0(>2000)$ \\
HS-sur-1 $|+|$ & $0 / 40$ & $0(>2000)$ \\
HS-mek-2|+) + HS-sur-1 $|+|$ & $0 / 31$ & $0(>1000)$ \\
HS-mek-2(S223ES227D) & $55 / 65$ & $20(>1500)$ \\
\hline
\end{tabular}

$(n)$ Number of transgenic animals examined.

${ }^{a}$ Constructs used for microinjection. The concentration of DNA used for microinjection is $20 \mu \mathrm{g} / \mathrm{ml}$ for all plasmids. The host strain for microinjection is N2. For HS-mek-2|+| construct, the wild type mek-2 cDNA was fused behind heat shock promoter hsp16-2 (pYW89) or hsp16-41 (pYW90). For HS-sur-1) +) construct, the wild type sur-1 cDNA was fused behind the heat shock promoter hspl6-2 (pYW66) or hsp 16-41 (pYW72). For HSmek-2 $(+)+$ HS-sur- $1(+)$ construct, it is pYW89+pYW66 or pYW90+ pYW72. For HS-mek-2(S223ES227D) construct, the mek-2(S223ES227D) cDNA fused behind the heat shock promoter hsp16-2 (pYW94) or hsp16-41 (pYW95).

${ }^{b}$ Transgenic lines displayed Muv phenotype/total transgenic lines examined $|n|$. Among 33 independent transgenic lines examined [HS-mek-2|+ $\mid$ ], 18 lines derived from the microinjection of pYW89 and 15 lines from pYW90. Among 40 transgenic lines examined [HS-sur-1|+1], 23 lines derived from the microinjection of pYW66, and 17 lines derived from pYW72. Among 31 transgenic lines examined [HS-mek-2|+ |+ HS-sur- $1|+|$ ), 22 lines derived from the microinjection of pYW89+pYW66, 9 lines derived from pYW90+pYW72. Among 65 transgenic lines examined [HS-mek-2(S223ES227D)], 34 lines derived from the microinjection of pYW94 and 31 lines derived from pYW95. Among 10 non-Muv transgenic lines, 6 of them displayed a high percentage of dead eggs.

'Percentage of Muv displayed by transgenic animals.

\section{mek-2(S223ES227D) is a gain-of-function mutation}

It has been shown recently that a gain-of-function mutation in mammalian MEK can be generated by substituting the two phosphorylation target serines with acidic amino acids, glutamic acid, or aspartic acid (Cowley et al. 1994; Mansour et al. 1994). To test whether such a mutant MEK protein can also be constitutively active in a developmental program such as vulva induction in $C$. elegans, we created corresponding changes in MEK-2 and demonstrated that the mek-2 gene is not only necessary but also sufficient for vulval differentiation. Mutant constructs that have the mek-2(S223ES227D) gene under the control of the heat shock promoters, hsp16-2 or hsp16-41, were microinjected into wild-type (N2) hermaphrodites. The transgenic animals were heat shocked at $37^{\circ} \mathrm{C}$ for $1 \mathrm{hr}$ at different developmental stages and then scored as adults (Sulston and Horvitz 1977). Most of the transgenic animals displayed pleiotropic defects, including a Muv phenotype and embryonic lethality after heat shock. Among 65 transgenic lines tested, 55 lines displayed a Muv phenotype (Table 2; Fig. 6C). Of the 10 non-Muv transgenic lines, 6 produced a high percentage of dead eggs (data not shown). The phenotypes varied, depending on the stages of the animals being heat shock treated. When the heat shock was applied during early embryogenesis, severe embryonic lethality occured at high frequency and very few transgenic animals appeared wild type (data not shown). When the heat shock was applied during early L1, all of the surviving transgenic animals displayed a dumpy (Dpy) phenotype while a few transgenic animals were Muv. When the animals were heat shocked at early L2, transgenic animals displayed mutant phenotypes such as Muv, (Dpy), small (Sma), gonad and hermaphrodite tail abnormality (Fig. 6D), and general sickness. Finally, when the animals were heat shocked at early L3, most of the transgenic animals were very sick with increased Muv percentage, though all of the pleiotropic phenotypes displayed in animals heatshocked at L2 were still present (data not shown). Nontransgenic control animals subjected to the same heat shock conditions described above were wild type /data not shown).

The Muv phenotype suggests that mek-2(S223ES227D) behaves as a gain-of-function mutation, as loss-of-function mutation of mek-2(h294) causes a Vul phenotype. The pleiotropic defects caused by mek-2(S223ES227D) suggest that mek-2 plays important roles in many aspects of worm development (Fig. 7). However, we cannot exclude the possibility that some of the dominant phenotypes might be results of the ectopic expression of the mutant mek-2 gene, as its expression is under the control of heat shock promoters.

\section{mek-2(S223AS227A) causes dominant-negative effects}

It has also been shown recently that changing both the phosphorylation target serines (S218 and S222) to alanines in human MEK1 results in a mutant MEK that cannot be phosphorylated and activated by Raf (Alessi et al. 1994; Zheng and Guan 1994). Human MEK1(S218AS222A) acts as a dominant-negative protein that blocks serum-induced DNA synthesis and reverts ras- or src-transformed cells (Cowley et al. 1994). To test the effect of an analogous mek-2 mutation in C. elegans, we created the corresponding changes in mek-2, mek2(S223AS227A). A plasmid that contains the mek2(S223AS227A) cDNA under the control of a heat shock promoter, hsp16-41, was microinjected into either a wild-type strain $(\mathrm{N} 2)$ or a strain that contained an activated let-60 mutation, let-60(n1046 gf). In the wild-type background, three independent transgenic lines tested displayed an Egl phenotype after heat shock before L2 or L3: $\sim 30 \%$ of the transgenic animals displayed an Egl phenotype, compared with $<1 \%$ in wild-type animals (Table 3). One possibility for an Egl phenotype is the failure of mek-2(S223AS227A) to form a wild-type vulva. To score vuval cell differentiation of the transgenic animals, we microinjected the HS-mek-2/S223AS227A) plasmid into $d p y-20(e 1282)$ animals along with the $d p y$ 20 gene (pMH86) as a marker (Han and Sternberg 1991). Among 21 transgenic animals that were Egl, 18 of them displayed a Vul phenotype. In the let-60(n1046) background, three of the four transgenic lines tested displayed suppression of the Muv phenotype and an Egl 
Table 3. Effects of microinjection of multiple copies of mek-2(S223AS227A)

\begin{tabular}{|c|c|c|c|}
\hline $\begin{array}{l}\text { Transgenic line } \\
\text { with HS-mek- } \\
\text { 2(S223AS227A) }\end{array}$ & Hot strain ${ }^{b}$ & $\begin{array}{l}\text { Percent } \\
\text { Muv (n })^{\mathrm{c}}\end{array}$ & $\begin{array}{l}\text { Percent } \\
\text { Egl }(\mathbf{n})^{\mathrm{d}}\end{array}$ \\
\hline & $\mathrm{N}$ & & \\
\hline & N 2 & & 86) \\
\hline 0 & let-60(n1046) & 23 & J.D. \\
\hline 8 & let-60(n1046) & 27 & N.D. \\
\hline \multicolumn{4}{|c|}{$\begin{array}{l}\text { n) Number of transgenic animals examined. } \\
\text { Independent transgenic lines analyzed. The construct used for } \\
\text { microinjection is HS-mek-2(S223AS227A): the mek-2(S223AS227A) } \\
\text { cDNA was fused behind a heat shock promoter hsp16-41 } \\
\text { pYW109). The construct concentration for microinjection is } \\
50 \mu \mathrm{g} / \mathrm{ml} \text {. Heat shock was performed at early L2 for } 1 \mathrm{hr} \text { at } \\
37^{\circ} \mathrm{C} \text {. } \\
\text { Host strain for microinjection. } \\
\text { Percentage of Muv. (N.A.) Not available. } \\
\text { Percentage of egg-laying defective. (N.D.) Not determined. }\end{array}$} \\
\hline
\end{tabular}

phenotype after heat shock before L2 or L3 larval stage (Table 3; Fig. 6F). Two independent transgenic lines displayed $\sim 27 \%$ and $28 \%$ Muv phenotype after heat shock at $37^{\circ} \mathrm{C}$ for $1 \mathrm{hr}$ at early L2, compared with $\sim 95 \%$ Muv in let-60(n1046) homozygous animals (Fig. 6E). The transgenic line that neither suppressed the Muv phenotype of an activated let-60(n1046) mutation nor displayed an Egl phenotype might not contain the HS-mek2(S223AS227A) construct. Heat shock itself did not suppress the Muv phenotype of an activated let-60 ras mutation, and the rol-6(d) plasmid (pRF4) alone caused neither an Egl phenotype nor the suppression of the Muv phenotype of the activated let-60(n1046) (data not shown).

When transgenic animals were heat shocked at an early embryonic developmental stage, a high percentage of dead eggs was observed (data not shown). This result may suggest that mek-2 plays an important role in C. elegans early embryogenesis. However, because the mutant mek-2 gene was under the control of a heat shock promoter, the embryonic lethal phenotype might be caused by a misexpression of the mek-2 mutant gene. When transgenic animals were heat shocked at early L1, the dominant-negative phenotypes were much less severe (data not shown). Because vulval induction starts at L3, the MEK-2(S223AS227A) protein expressed in L1 might not be stable enough to cause a dominantnegative effect in L3. These results showed that mek2(S223AS227A) behaved as a dominant-negative mutation as both the suppression of the Muv phenotype of an activated let-60 ras mutation and the Vul phenotype were associated with the mek-2 loss-of-function mutations. A kinase-deficient mutant, MEK-2(K102M), resulting from the substitution of the catalytic essential lysine residue 102 by a methionine, was also tested as a dominant-negative mutant. Interestingly, mek2(K102M) was not an effective dominant-negative muta- tion when similar experiments were performed /data not shown).

\section{Discussion \\ C. elegans $M E K-2$ functions as a MAP kinase kinase}

Because MEK proteins are highly conserved among different organisms, we were able to design degenerate oligonucleotides in the conserved kinase domains and use them to isolate a $C$. elegans MEK homolog. We have shown that the mek-2 gene product is structurally and functionally similar to the human MEK proteins. By in vitro kinase assays, the MEK-2 protein possesses the biochemical properties of MAP kinase kinase. It can activate the human ERK1 protein by phosphorylation on both threonine and tyrosine, indicating it is a dual specific kinase. Furthermore, MEK- 2 itself can be phosphorylated and activated by mammalian Raf, the upstream activator of mammalian MEK. Although the $C$. elegans Lin-45 Raf protein has not been tested for activation of MEK-2 because we are unable to produce active recombinant Raf, it is likely that the C. elegans Raf directly activates MEK- 2 in vivo. Our genetic analysis of mek-2 has identified its role in vulval induction and other developmental processes, and the biochemical studies of MEK-2 suggest that it acts between Lin-45 Raf and Sur-1 MAP kinase (Fig. 7).

\section{Loss-of-function mutations in mek- 2 define its roles in multiple developmental events}

The role of the mek-2 gene in specific developmental events is demonstrated by the phenotypes of two mek-2 loss-of-function mutations and by the dominant phenotypes generated by ectopic expression of different dominant mutant mek-2 genes. Our genetic analysis of the two mek-2 loss-of-function mutations, ku114 and h294, is consistent with the genetic analysis of other mek-2 mutations by Kornfeld et al. (this issue) and Church et al. (1995). mek-2(h294) is a severe loss-of-function mutation that displays highly penetrant Vul and sterile phenotypes, suggesting essential roles for the gene in vulval differentiation and germ-line development. Sterility is also associated with mutations in other genes acting in the vulval signal transduction pathway, like let-23 and let-60 (Aroian and Sternberg 1991; Han et al. 1993). A mutation in the sur-1 gene, oz140, also caused a highly penetrant sterile phenotype (Church et al. 1995; T. Schedl; M.R. Lackner and S.K. Kim; both pers. comm.).

In contrast to mek-2(h294), mek-2(ku114) appears to be a relatively weak mutation. Although ku114 completely suppressed the Muv phenotype of an activated let-60 ras mutation, vulval cell lineages in animals homozygous for ku114 appear normal. Animals homozygous for both mek-2(ku114) and let-60(n1046 gf) also displayed a partial Egl phenotype that is absent from mek2(ku114) single mutants. This synthetic egg-laying phenotype is likely to be the result of defects in other aspects of the C. elegans egg-laying machinery (Thomas 
et al. 1990; M. Sundaram and M. Han, in prep.). We have also shown that mek-2(ku114) homozygotes display an $8 \%$ larval lethality, indicating a role of the gene in early development. Larval lethality is associated with many mutations in most of the key genes acting in the vulval signaling pathway and has been proposed to be the null phenotype for these genes, including let-60 ras, lin-45 raf and sur-1 MAP kinase (Han et al. 1990, 1993; Wu and Han 1994). The phenotype of null alleles of mek-2 is likely to be complete larval lethality.

The molecular lesions of $h 294$ (a E238K change) and of ku114 (a P237S change) are consistent with the severity of their phenotype. Based on crystallographic studies of cAMP-dependent protein kinase (PKA) (Knighton et al. 1991), Glu-238 of MEK-2 may form a salt bridge with Arg-348. Substitution of Glu-238 with a lysine residue in mek-2(h294) would eliminate the salt bridge with Arg348 , thus severely affecting the protein structure of MEK-2, leading to a reduction of its kinase activity. Pro237 in MEK-2, adjacent to Glu-238, is also highly conserved in the protein kinase family and corresponds to Pro-207 in PKA. Substitution of Pro-237 with a serine residue may affect the protein structure of MEK-2 in such a way that it weakens the salt bridge between Glu238 and Arg-348, resulting in a reduction of the protein kinase activity. Consistent with the prediction from three-dimensional structures, we have shown that mek2(ku114) has a relatively weak mutant phenotype: It completely suppressed the Muv phenotype of an activated let-60 mutation, but animals homozygous for the ku114 mutation have essentially wild-type vulval differentiation.

\section{Changes in the phosphorylation target sites of MEK-2 lead to dominant mutant phenotypes}

In mammalian cells, phosphorylation of the two serine residues at positions 218 and 222 of human MEK1 by Raf is necessary and sufficient for activation (Zheng and Guan 1994; Alessi et al. 1994). Double mutations of these two serine residues to acidic amino acids result in a constitutively active form of MEK, which is necessary and sufficient for NIH-3T3 cell transformation and PCl2 cell differentiation (Cowley et al. 1994). We have demonstrated further in this study that a similar mutation of C. elegans mek-2, mek-2(S223ES227D), was hyperactive and caused multiple defects in developmental programs. Expression of multiple copies of a mek-2(S223ES227D) cDNA construct under the control of a heat shock promoter generated a variety of pleiotropic defects, which included Muv, Dpy, Sma, sickness, gonad and hermaphrodite tail abnormality, and embryonic lethality. Caution should be taken in interpreting the phenotypes because the heat shock promoters were used. These phenotypes are either attributable to hyperactivity of the mek-2(S223ES227D) gene in cell signaling pathways in which mek-2 normally functions or to abnormal expression of the constitutively active mutant gene in cells in which the wild-type mek-2 does not normally function. We believe that at least some of these dominant pheno- types are indications of the normal function of mek-2 in multiple developmental events. For example, the Muv phenotype attributable to ectopic expression of mek2(S223ES227D) is likely to be the result of hyperactivation of mek-2 in the let-60 ras-mediated pathway because the normal function of mek-2 in the pathway is established by the Vul phenotype of loss-of-function mek-2 mutations. Other phenotypes, such as larval lethality and sterility, are also seen in loss-of-function mutations in mek-2, sur-1, let-60, and other genes acting in the pathway.

The dominant effects caused by microinjecting mek2(S223ES227D) are a result of the constitutive activation of the MEK-2 kinase. We have shown that ectopic expression of mek-2|+|, sur-1|+|, or mek-2|+| and sur$1(+)$ together results in no obvious phenotypes, although a low percentage of Dpy transgenic animals were observed (data not shown). These studies are consistent with recent results with mammalian MEK that these enzymes are tightly regulated, not at the level of the enzyme quantity, but at the level of protein phosphorylation.

It has been observed with human MEK1 that the substitution of the two serine residues with alanines results in a dominant-negative form of the protein that can block serum-induced DNA synthesis and suppress ras or src transformation (Cowley et al. 1994). We have demonstrated in this study that a similar change in mek-2, mek-2(S223AS227A), also results in a dominant-negative mutant phenotype in $C$. elegans. Interestingly, the kinase-deficient mutant MEK-2(K102M) showed little dominant-negative effects (data not shown). Although the mechanism of such a dominant-negative effect is not clear, MEK-2(S223AS227A) possibly blocks function of the upstream Raf, downstream MAP kinase, or other factors working in the signal transduction pathway. We propose that MEK-2(S223AS227A) is likely to block the function of Raf rather than MAP kinase. First, MAP kinase is expressed in mammalian cells at a level much higher than Raf, and it is easier to sequester a protein that is expressed at a low level such as Raf than a protein expressed at high abundance such as MAP kinase. Second, activation of MEK by Raf involves binding of MEK to Raf, phosphorylating the two serine residues, and releasing the phosphorylated MEK from Raf. Mutant MEK-2(S223AS227A) should be able to bind Raf but not be phosphorylated by Raf. Such a nonproductive complex may result in a stable association of MEK-2(S223AS227A) with Raf, thus titrating Raf away from endogenous MEK protein. In contrast, the kinase-deficient MEK-2(K102M) protein, which shows a much weaker dominant-negative effect than MEK2(S223AS227A), is expected to bind Raf, be phosphorylated by Raf, and then dissociate from Raf. Therefore, no stable complex between MEK-2(K102M) and Raf should be formed. Our results are consistent with the hypothesis that the dominant-negative effects of MEK2(S223AS227A) are attributable to the sequestering of Raf. Further biochemical and gentic studies are required to test this hypothesis. 
MAP kinase activation has been observed in mammalian cells stimulated with a wide variety of extracellular stimuli, including mitogenic growth factors, differentiation factors, T-cell antigens, cytokines, and tumor promoters (Cobb et al. 1991). The pleiotropic effects of mek-2 mutation in C. elegans further demonstrate the multiple roles of MAP kinase pathways in regulation of cell growth, differentiation, and development. The gainof-function mutation and dominant-negative mutation of mek-2 characterized in this report will provide useful tools for understanding the physiological functions of MAP kinase. Future studies to uncover roles of mek-2 in C. elegans developmental events in addition to vulval induction are likely to generate new insights of the MAP kinase pathway and Ras signaling mechanism.

\section{Materials and methods}

\section{Cloning of mek-2}

Two degenerate oligonucleotides were designed on the basis of the conserved amino acid sequences of MEKs. Oligonucleotides CTTGGATCCTA|C,T)AT(A,C,T)GTNTT/C,T)TA (for amino acids YIVGFY corresponding to residues $130-136$ of MEK-2; Fig. 2) and

CTTGGATCC $(G, T)(C, T)$ TCNGGN $(C, G)(A, T) C A T(A, G) T A$ (for amino acids YMSPER corresponding to residues 234-239) were synthesized. The underlined sequences denote $\mathrm{BamHI}$ restriction sites incorporated in the oligonucleotides. These two primers were used in PCR for 35 cycles at $94^{\circ} \mathrm{C}$ for $1 \mathrm{~min}, 50^{\circ} \mathrm{C}$ for $1 \mathrm{~min}$, and $72^{\circ} \mathrm{C}$ for $1 \mathrm{~min}$ using a $\mathrm{C}$. elegans cDNA library (Stratagene) as the template.

To isolate mek-2 cDNA clones, the $0.35-\mathrm{kb}$ PCR clone, which showed strong sequence identity to MEK, was used to screen a mixed stage C. elegans cDNA library (Stratagene) under standard conditions (Maniatis et al. 1982). Among 300,000 plaques screened, four positive clones were identified and DNA sequence was determined in both strands using synthetic oligonucleotides.

Because the cDNA clones were incomplete at their $5^{\prime}$ ends, the same cDNA library was used as a template for PCR to isolate the $5^{\prime}$ region of mek-2 cDNA. A T7 primer [annealing to the $\mathrm{SK}$ (-) vector] and mek-2-2N primer [AAGCCCCGTAGAATCCA annealing to nucleotides $424-440$ in Fig. 2) were used in PCR $\left(94^{\circ} \mathrm{C}\right.$ for $1 \mathrm{~min}, 52^{\circ} \mathrm{C}$ for $1 \mathrm{~min}, 72^{\circ} \mathrm{C}$ for $1 \mathrm{~min}$, for 30 cycles). DNA between 0.4 and $0.8 \mathrm{~kb}$ was recovered from an agarose gel and used as a template for a second round of PCR in which an SK primer [annealing to the $\mathrm{SK} \mid-$ ) vector $3^{\prime}$ to the $\mathrm{T} 7$ primer] and the mek-2-1N primer (TTTCAGCTGTTCTTCTA, annealing to nucleotides $141-158$ in Fig. 2) were used for amplification. The PCR product was subcloned into Bluescript $\mathrm{SK}(-)$ and then sequenced.

Total chromosomal DNA was isolated from a yeast strain containing the YAC clone Y54E 10 and digested with EcoRI. The $E c o R I$-digested DNA $(0.2 \mu \mathrm{g})$ was ligated into EcoRI digested $\lambda$ Ziplox vector $(0.5 \mu \mathrm{g}$, GIBCO BRL $)$ to construct a yeast genomic library. We obtained a library of $5 \times 10^{6}$ independent clones. This library was directly screened for the mek-2 gene without amplification. From the mek-2 cDNA clone, three EcoRI fragments $(0.15,1.0$, and $0.18 \mathrm{~kb})$ (Fig. 4) were isolated and labeled separately. Screening of the genomic library was performed under the same conditions as for the cDNA library screening. Junctions of exons and introns were determined by DNA sequencing. Intron 1 was determined by direct sequencing of PCR products.

\section{Plasmid construction}

To express a GST-MEK-2 fusion protein in E. coli, the mek-2 cDNA clone was amplified by PCR to introduce convenient restriction sites for subcloning into the vector pGEX-KG /Guan and Dixon 1991). The $5^{\prime}$-end and $3^{\prime}$-end primers were GCTCTAGACTCGAGCGGAAACGGCGT (the underlined sequence denotes an $\mathrm{XbaI}$ restriction site) and AGCGTCGACAAAGAGACATCGAA (the underlined sequence denotes a Sall restriction site), respectively. The $1.2-\mathrm{kb}$ PCR product was digested with $\mathrm{XbaI}$ and SalI and subcloned into pGEX-KG to produce pGEX-MEK-2. The cloning junction and the DNA sequence of the mek-2 portion were confirmed.

To construct a full-length clone of mek-2 cDNA clone, pYW88, we amplified by PCR a mek-2 cDNA clone, pCemek-2, which lacks the first two amino acids by using a $5^{\prime}$ primer oligonucleotide OYW38: 5'-GCTCTAGATGTCGAGCGGAAAACGGCGTAATCC-3'. To construct pYW91, which contains the mek-2(S223ES227D) cDNA, we used a modified PCR-based site-directed mutagenesis method. The two internal oligonucleotides are OYW43 (AAAGTCGTTGGCCATCTCATCAATCAACATTCCAGAG) and OYW44 (GATGAGATGGCCAACGACTTTGTCGGAACGAGGAG). The constructs were sequenced to ensure that there were no sequence changes attributable to PCR amplifications.

Site-directed mutagenesis was also performed using the Altered Site Mutagenesis System (Promega). The XbaI-Sall fragment of mek-2 was subcloned from pGEX-MEK-2 /described above) into the pALTER vector (Promega). Oligonucleotide TGGCTCGGAATGCTTGTACA was used to change the lysine at codon 102 to a methionine. Oligonucleotide TTGATTGATGCGATGGCCAACGCATTTGTCG was used to change the Ser223 and Ser-227 to alanines. Nucleotide changes in each mutant were confirmed by DNA sequencing.

pYW94 was constructed as follows: pYW91 [mek2(S223ES227D)] cDNA was cloned into SK $(+\mid X b a I$ and EcoRI sites and digested with $\mathrm{XbaI}$ and $\mathrm{KpnI}$; and the insert band was isolated and then ligated with the band isolated from the vector pPD49.78 (contains hsp16-2), which was digested with NheI and KpnI. By the same procedure, we constructed pYW95 by using pPD49.83 (contains hsp16-41). Similar methods were used to construct pYW89, pYW90, pYW66, pYW72, and pYW109.

\section{Kinase assay}

Plasmid pGEX-MEK-2 was transformed into E. coli BL21 to express GST-MEK-2 fusion protein following published procedures (Guan and Dixon 1991). The fusion protein was purified by glutathione agarose affinity chromatography. Recombinant human ERKI was prepared as described previously (Zheng and Guan 1993).

Purified recombinant human ERK $1(1 \mu \mathrm{g})$ was phosphorylated by $2 \mu \mathrm{g}$ of GST-MEK-2 in $20 \mu \mathrm{l}$ of kinase assay buffer $(18 \mathrm{mM}$ HEPES at pH 7.5, $10 \mathrm{~mm}$ magnesium acetate, $50 \mathrm{~mm}$ ATP) containing $5 \mu \mathrm{Ci}$ of $\left[\gamma^{32} \mathrm{P}\right] \mathrm{ATP}$. Phosphoamino acid analysis was performed following published methods (Boyle et al. 1991). Activity of GST-MEK-2 was determined by an in vitro ERK activation assay. Purified recombinant ERK1, which had a very low basal activity, was activated by various amounts of GSTMEK-2 $(0.3-1.5 \mu \mathrm{g})$ at $30^{\circ} \mathrm{C}$ for $10 \mathrm{~min}$ in $20 \mu \mathrm{l}$ kinase assay buffer. The activity of ERK was determined using MBP as a substrate (Zheng and Guan 1993).

Swiss 3 T3 cells were cultured in Dulbecco's modified Eagle medium supplemented with $10 \%$ calf serum (GIBCO BRL). Cells were grown to confluency and starved for $24 \mathrm{hr}$ in DMEM supplemented with $0.1 \%$ serum. The starved cells were stimu- 
lated with EGF ( $100 \mathrm{ng} / \mathrm{ml}$, Sigma) for 2-5 min and harvested in lysis buffer (25 mM HEPES, at pH 7.5, $0.2 \mathrm{~mm}$ PMSF, 0.05\% 2 -mercaptoethanol, $1 \%$ Triton $\mathrm{X}-100,2 \mathrm{~mm}$ sodium vanadate, and $50 \mathrm{~mm} \mathrm{NaF}$ ). Cells were sonicated for $10 \mathrm{sec}$ and centrifuged $(10,000 \mathrm{~g})$ for $20 \mathrm{~min}$ at $4^{\circ} \mathrm{C}$. The supernatant was used for immunoprecipitation with anti-Raf antibody. Anti-Raf or control serum $(5 \mu \mathrm{l})$ was used in immunoprecipitation of $2 \mathrm{mg}$ protein of Swiss 3T3 cell lysates on ice for $1 \mathrm{hr}$. Protein A-agarose $\{20$ $\mu \mathrm{l}$, Pierce) was added to the immunoprecipitation reaction for $30 \mathrm{~min}$. The immunocomplex was washed three times with cell lysis buffer followed by one washing with the kinase assay buffer. The immunoprecipitated Raf was used to activate $1.5 \mu \mathrm{g}$ of GST-MEK-2 in $30 \mu \mathrm{l}$ kinase assay buffer for $20 \mathrm{~min}$ at $30^{\circ} \mathrm{C}$ with gentle shaking. The Raf protein complexed with antibody and protein A-agarose was removed by centrifugation. The activated GST-MEK-2 $(0.6 \mu \mathrm{g})$ was used to activate $0.6 \mu \mathrm{g}$ of ERK following the procedures described above. ERK activity was determined by the myelin basic protein (MBP) kinase assay. Half of the reaction was analyzed by an $18 \%$ SDS-PAGE followed by autoradiography. The other half was quantitated by scintillation counting of ${ }^{32} \mathrm{P}$ incorporation into MBP as described above for the MBP kinase assay. GST-MEK-2 without Raf activation was treated identically as a control.

\section{Isolation and genetic characterization of mek-2(ku114) and mek-2(h294)}

Methods for the culturing, handling, and genetic manipulation were as described previously (Brenner 1974; Wood et al. 1988). All genetic experiments were performed at $20^{\circ} \mathrm{C}$. mek-2(ku114) was isolated as a recessive suppressor of the Muv phenotype of let-60(n1046 gf). The mutagenesis and screening procedures have been described previously (Wu and Han 1994). mek2(h294) [previously called let-537(h294)] was isolated in the laboratory of A. Rose (University of British Columbia, Vancouver, Canada) in a screen for lethal or sterile mutations on the left arm of chromosome I (McKim 1990). To score vulval induction of animals homozygous for mek-2(h294), sterile animals segregated from a strain with genotype mek-2(h294) $+/+$ unc74(e883) were picked. The methods to score the percentage of vulval induction, egg-laying defective, larval lethal phenotype were performed as described (Wu and Han 1994).

\section{Genetic mapping}

Standard two-factor crosses using genetic markers were performed to position ku114 on the genetic map (Brenner 1974). From mothers of ku114 $++1+d p y-5(e 61)$ unc-29(e403); let60 (n1046), 21 egg-laying defective worms, which were homozygous for ku114 and let-60(n1046), were picked. Five of them segregated Dpy Unc animals whose genotypes were ku114+ $+/$ ku114 dpy-5(e61) unc-29(e403); let-60(n1046). From a strain of ku114 + + I+ unc-11(e47) dpy-5(e61); let-60(n1046), 21 egglaying defective worms, homozygous for ku114 and let60(n1046), were picked. Four of them segregated Dpy non-Unc animals whose genotypes were ku114 $++/ k u 114+d p y$ 5(e61); let-60(n1046), whereas none of the $21 \mathrm{Egl}^{-}$animals segregated Unc progenies.

\section{Microinjection experiment}

DNA isolation, analysis, and subcloning were performed by standard methods. Microinjection of cloned DNAs into the gonadal syncytia of $C$. elegans hermaphrodites was carried out as described previously (Han and Sterberg 1990; Mello et al. 1991). Each transformation result was scored with multiple indepen- dent transgenic lines. All plasmids were injected at a concentration of $\sim 20 \mu \mathrm{g} / \mathrm{ml}$. Most of the injection experiments stated in this paper were performed by coinjection of a rol6(d) plasmid (pRF4) as a dominant marker for transformation (Mello et al. 1991). A strain of ku114; let-60(n1046) was used as the host strain to determine whether the mek-2 gene can rescue the mutant phenotype of ku114. A mixed population of transgenic animals (most at embryo, L1, or L2 stages) were heat shock treated at $34^{\circ} \mathrm{C}$ for $4 \mathrm{hr}$ for 2 consecutive days. The plates were kept in an incubator at $20^{\circ} \mathrm{C}$ between the heat shocks. The Muv phenotype of roller animals were examined 2 days later.

Experiments analyzing the transgenic lines from the injection of the constructs pYW89, pYW90, pYW89+pYW66, and pYW $90+$ pYW72, were as follows: 1-10 adult transgenic animals were picked to each plate, allowed to lay eggs overnight at $15^{\circ} \mathrm{C}$, and removed $\sim 12 \mathrm{hr}$ later. At the time of removal of the adult worms, the plates contained mostly eggs and a few L1 larvae. Heat shock experiments were executed at $34^{\circ} \mathrm{C}$ for $4 \mathrm{hr}$ at different developmental stages, embryonic, L1, L2, and L3. Adult transgenic animals were scored for their phenotypes. Experiments analyzing the transgenic lines from the injection of the constructs of pYW66, pYW72, pYW71, and pYW73 were as follows: In one set of experiments, adult transgenic animals from each transgenic line were transferred to five different plates, allowed to lay eggs for $\sim 2 \mathrm{hr}$, and removed. Each of the five plates was heat shocked at $34^{\circ} \mathrm{C}$ for $1 \mathrm{hr}$ or at $37^{\circ} \mathrm{C}$ for $2 \mathrm{hr}$ as embryo, L1, L2, L3, or L4 stage accordingly, and the adult roller animals were scored for their phenotypes. In another set of experiments, the adult transgenic animals from different transgenic lines were transferred to new plates and were allowed to lay eggs for $2 \mathrm{hr}$. These adult worms were then removed. All of the plates were heat shocked at $34^{\circ} \mathrm{C}$ for $\sim 3 \mathrm{hr}$ at embryo, L1, L2, and L3 stages. The adult transgenic animals were scored for their phenotypes. To determine that the construct pYW66 or pYW72 was able to rescue the mutant phenotype of sur-1(ku1), each construct was microinjected into the host strain, sur-1(ku1); let-60(n1046). The experimental conditions were similar to that used in the rescue experiment of ku114.

\section{Acknowledgments}

We thank A. Rose for kindly providing us the h294 mutation, S. Decker for providing anti-Raf serum, D. Green and Y. Han for isolating and mapping the ku114 mutation, T. Schedl for the oz140 mutation, S. Noh for helping in the isolation of the mek-2 gene, $\mathrm{X}$. Wu for excellent technical assistance, A. Coulson for genomic library and YACs, the M. Edgely and W. Wood laboratory for various $C$. elegans strains, and A. Fire for heat shock promoters. Some of the strains were provided by the Caenorhabditis Genetics Center, which is funded by the National Institutes of Health National Center for Research Resources. We thank A. Rose, J. Yochem, J.E. Dixon, S. Mansour, N. Ahn, and H. Chen for stimulating discussion during this study. We thank E. Lambie, K. Kornfield, S. Mansour, N. Ahn for communicating unpublished results; and J. Yochem, E. Butch, L. Mathews, C. Minth, N. Singh, M. Sundaram, and J. Powell-Coffman for comments on the manuscript. M.H. is a Lucille P. Markey Scholar, a Basal O'Connor Scholar of the March of Dimes Foundation, and a Searle Scholar. This research has been supported by U. S. Public Health Service grants (GM47869) to M.H. and (GM51586) to K.L.G., American Cancer Society grant (BE-171) to K.L.G, and a grant from the Council for Tobacco Research to M.H. Computer-assisted sequence analysis was supported by the General Clinical Research Center (grant M01-RR00042). 
The publication costs of this article were defrayed in part by payment of page charges. This article must therefore be hereby marked "advertisement" in accordance with 18 USC section 1734 solely to indicate this fact.

\section{Note added in proof}

The sequence data for $C$. elegans mek-2 have been deposited into the GenBank data library under accession number U21107.

\section{References}

Ahn, N.G., R. Seger, and E.G. Kreb. 1992. The mitogen-activated protein kinase activator. Curr. Opin. Cell Biol. 4: 992999.

Alessi, D.R., Y. Saito, D.G. Campbell, P. Cohen, G. Sithanandam, U. Rapp, A. Ashworth, C.J. Marshall, and S. Cowley. 1994. Identification of the sites in MAP kinase kinase-1 phosphorylated by p74raf-1. EMBO / 13: 1610-1619.

Aroian, R.V. and P.W. Sternberg. 1991. Multiple functions of let-23, a Caenorhabditis elegans receptor tyrosine kinase gene required for vulval induction. Genetics 128: 251-267.

Aroian, R.V., M. Koga, J. E. Mendel, Y. Ohshima and P.W. Sternberg. 1990. The let-23 gene necessary for Caenorhabditis elegans vulval induction encodes a tyrosine kinase of the EGF receptor subfamily. Nature 348: 693-699.

Blumer, K.J. and G. Johnson. 1994. Diversity in function and regulation of MAP kinase pathways. Trends Biochem. Sci. 19: $236-240$.

Boulton, T.G., G.D. Yancopoulos. J.S. Gregory. C. Slaughter. C. Moomaw. J. Hsu, and M.H. Cobb. 1990. An insulin-stimulated protein kinase similar to yeast kinases involved in cell cycle control. Science 249: 64-67.

Boyle, W.J., P. van de Geer, and T. Hunter. 1991. Phosphopeptide mapping and phosphoamino acid analysis by two-dimensional separation on thin-layer cellulose plates. Methods Enzymol. 201: 110-149.

Brenner, S. 1974. The genetics of Caenorhabditis elegans. Genetics 77: 71-94.

Chamberlin, H.M. and P.W. Sternberg. 1993. Multiple cell interactions are required for fate specification during male spicule development in Caenorhabditis elegans. Development 118: 297-324.

Church, D.L., K.L. Guan, and E.J. Lambie. 1995. mek-2, mpk$1 /$ sur-1 and let 60 ras are required for meiotic cell cycle progression in C. elegans. Development (in press).

Clark, S.G., M.J. Stern, and H.R. Horvitz. 1992. C. elegans cellsignalling gene sem -5 encodes a protein with $\mathrm{SH} 2$ and $\mathrm{SH} 3$ domain. Nature 356: 340-344.

Cobb, M.H., T.G. Boulton, and D.J. Robbins. 1991. Extracellular signal-regulated kinases: ERKs in progress. Cell Regul. 2: 965-978.

Cowley, S., H. Paterson, P. Kemp, and C.J. Marshall. 1994. Activation of MAP kinase is necessary and sufficient for PC12 differentiation and for transformation of NIH $3 \mathrm{~T} 3$ cells. Cell 77: 841-852.

Crews, C.M. and R.L. Erikson. 1992. Purification of a murine protein-tyrosine/threonine kinase that phosphorylates and activates the Erk-1 gene product: Relationship to the fission yeast byrl gene product. Proc. Natl. Acad. Sci. 89: 82058209.

-1993. Extracellular signals and reversible protein phosphorylation: What to mek of it all. Cell 74: 215-217.

Davis, R.J. 1994. The mitogen-activated protein kinase signal transduction pathway. J. Biol. Chem. 268: 14553-14556.
Dent, P., W. Haser, T.A.J. Haystead, L.A. Vincent, T.M. Roberts, and T.W. Sturgill. 1992. Activation of mitogen-activated protein kinase kinase by v-Raf in NIH 3T3 cells and in vitro. Science 257: 1404-1407.

Gille, H., A.D. Sharrocks, and P.E. Shaw. 1992. Phosphorylation of transcription factor p62TCF by MAP kinase stimulates ternary complex formation at c-fos promoter. Nature 358: 414-417.

Guan, K.-L. 1994. The mitogen activated protein kinase signal transduction pathway: From the cell surface to the nucleus. Cell. Signalling 6: 581-589.

Guan, K.-L. and J.E. Dixon. 1991. One step purification of eukaryotic proteins expressed in E. coli. An improved thrombin cleavage and purification procedure of fusion proteins with glutathione-S-transferase. Anal. Biochem. 192: 262267.

Han, M. and P.W. Sternberg. 1990. let-60, a gene that specifies cell fates during C. elegans vulval induction, encodes a ras protein. Cell 63: 921-931.

- 1991. Analysis of dominant-negative mutations of the Caenorhabditis elegans let-60 ras gene. Genes \& Dev. 5: 2188-2198.

Han, M., R. Aroian, and P.W. Sternberg. 1990. The let-60 locus controls the switch between vulval and non-vulval cell types in C. elegans. Genetics 126: 899-913.

Han, M., A. Golden, Y. Han, and P.W. Sternberg. 1993. C. elegans lin-45 raf gene participates in let-60 ras-stimulated vulval differentiation. Nature 363: 133-140.

Herman, R.K. and E.M. Hedgecock. 1990. Limitation of the size of the vulval primordium of Caenorhabditis elegans by lin15 expression in surrounding hypodermis. Nature 348: 169171.

Hill, R.J. and P.W. Sternberg. 1992. The gene lin-3 encodes an inductive signal for vulval development in C. elegans. $\mathrm{Na}$ ture 358: 470-476.

Hill, C.S., R. Marais, S. John, J. Wynne, S. Dalton, and R. Treisman. 1993. Functional analysis of a growth factor-responsive transcription factor complex. Cell 73: 395-406.

Horvitz, H.R. and P.W. Sternberg. 1991. Multiple intercellular signalling systems control the development of the C. elegans vulva. Nature 351: 535-541.

Howe, L.R., S.J. Leevers, N. Gomez, S. Nakielny, P. Cohen, and C. Marshall. 1992. Activation of the MAP kinase pathway by the protein kinase raf. Cell 71: 335-342.

Knighton, D.R., J.H. Zheng, L.F. Ten Eyck, N.H. Xuong, S.S. Taylor, and J.M. Sowadski. 1991. Structure of a peptide inhibitor bound to the catalytic subunit of cyclic adenosine monophosphate-dependent protein kinase. Science 253: 414-420.

Kornfeld, K., K.L. Guan, and H.R. Horvitz. 1995. The C. elegans gene mek-2 is required for vulval induction and encodes a protein similar to the protein kinase MEK. Genes \& Dev. (this issue).

Krause, M. and D. Hirsh. 1987. A trans-spliced leader sequence on actin mRNA in Caenorhabditis elegans. Cell 49: 753761.

Kyriakis, J.M., H. App, X.-F. Zhang, P. Banerjee, D.L. Brautigan, U.R. Rapp, and J. Avruch. 1992. Raf-1 activates MAP kinasekinase. Nature 358: 417-421.

Lackner, M.R., K. Kornfeld, L.M. Miller, H.R. Horvitz, and S.K. Kim. 1994. A MAP kinase homolog, mpk-1, is involved in ras-mediated induction of vulval cell fates in $C$. elegans. Genes. \& Dev. 8: 160-173.

Lin, L.L., M. Wartmann, A.Y. Lin, J.L. Knopf, A. Seth, and R.J. Davis. 1993. PLA2 is phosphorylated and activated by MAP kinase. Cell 72: 269-278. 
Maniatis, T., E.F. Fritsch, and J. Sambrook. 1982. Molecular cloning: A laboratory manual. Cold Spring Harbor Laboratory Press, Cold Spring Harbor, New York.

Mansour, S.J., W.T. Matten, A.S. Hermann, J.M. Candia, S. Rong, K. Fukasawa, G.F. Vande Woude, and N.G. Ahn. 1994. Transformation of mammalian cells by constitutively active MAP kinase kinase. Science 265: 966-970.

Marais, R., J. Wynne, and R. Treismann. 1993. The SRF accessory protein Elk-1 contains a growth factor-regulated transcriptional activation domain. Cell 73: 381-393.

McCormick, F. 1993. How receptors turn Ras on. Nature 363: 15-16.

McKim, K.S. 1990. "Analysis of chromosome rearrangements in Caenorhabditis elegans." Ph.D. thesis, The University of British Columbia, Vancouver.

Mello, C.C., J.M. Kramer, D. Stinchcomb, and V. Ambros. 1991. Efficient gene transfer in C. elegans after microinjection of DNA into germline cytoplasm: Recombination drives the assembly of heritable transgenic structures. EMBO $/$. 10: 3959-3970.

Nadin-Davis, S.A. and A. Nasim. 1988. A gene which encodes a predicted protein kinase can restore some functions of the ras gene in fission yeast. EMBO I. 7: 985-993.

Northwood, I.C., F.A. Gonzalez, M. Wartmann, D.L. Raden, and R.J. Davis. 1991. Isolation and characterization of two growth factor-stimulated protein kinases that phosphorylate the epidermal growth factor receptor at threonine 669. $I$. Biol. Chem. 266: 15266-15276.

Seger, R., N.G. Ahn, J. Posada, E.S. Munar, A.M. Jensen, J.A. Cooper, M.H. Cobb, and E.G. Krebs. 1992a. Purification and characterization of mitogen-activated protein kinase activator(s) from epidermal growth factor-stimulated A431 cells. $J$. Biol. Chem. 267: 14373-14381.

Seger, R., D. Seger, F.J. Lozeman, N.G. Ahn, L.M. Graves, J.S. Campbell, L. Ericsson, M. Harrylock, A.M. Jensen, and E.G. Krebs. 1992b. Human T-cell mitogen-activated protein kinase kinases are related to yeast signal transduction kinases. J. Biol. Chem. 267: 25628-25631.

Stokoe, D., D.G. Campbell, S. Nakielny, H. Hidaka, S.J. Leevers, C.J. Marshall, and P. Cohen. 1992. MAPKAP kinase-2; a novel protein kinase activated by mitogen-activated protein kinase. EMBO J. 11: 3985-3994.

Stringham, E.G., D.K. Dixon, D. Jones, and E.P. Candido. 1992. Temporal and spatial expression patterns of the small heat shock (hsp16) genes in transgenic Caenorhabditis elegans. Mol. Biol. Cell. 3: 221-233.

Sturgill, T.W., L.B. Ray, E. Erikson, and J.L. Maller. 1988. Insulin-stimulated MAP-2 kinase phosphorylates and activates ribosomal protein S6 kinase II. Nature 334: 715-718.

Sulston, J. and H.R. Horvitz. 1977. Postembryonic cell lineages of the nematode Caenorhabditis elegans. Dev. Biol. 56: 110-156.

Teague, M.A., D.T. Chaleff, and B. Errede. 1986. Nucleotide sequence of the yeast regulatory gene STE7 predicts a protein homologous to protein kinases. Proc. Natl. Acad. Sci. 83: $7371-7375$.

Thomas, J.H., M.J. Stern, and H.R. Horvitz. 1990. Cell interactions coordinate the development of the C. elegans egg-laying system. Cell 62: 1041-1052.

Tsuda, L., Y. Inoue, M.A. You, M. Mizuno, M. Hata, Y.M. Limm, T. Adachi-Yamada, H. Ryo, Y. Masamune, and Y. Nishida. 1993. A protein kinase similar to MAP kinase activator acts downstream of the Raf kinase in Drosophila. Cell 72: 407-414.

Wood, W.B. and the Community of C. elegans Researchers. 1988. The nematode Caenorhabditis elegans. Cold Spring
Harbor Laboratory, Cold Spring Harbor, New York.

Wu, Y. and. M. Han. 1994. Suppression of activated Let-60 Ras protein defines a role of Caenorhabditis elegans Sur-1 MAP kinase in vulval differentiation. Genes \& Dev. 8: 147-159.

Zheng, C.F. and K.L. Guan. 1993. Cloning and characterization of two distinct human extracellular signal-regulated kinase activator kinases, MEK1 and MEK2. I. Biol. Chem. 268: 11435-11439.

1994. Activation of MEK family kinases requires phosphorylation of two conserved Ser/Thr residues. EMBO $/$. 13: 1123-1131. 


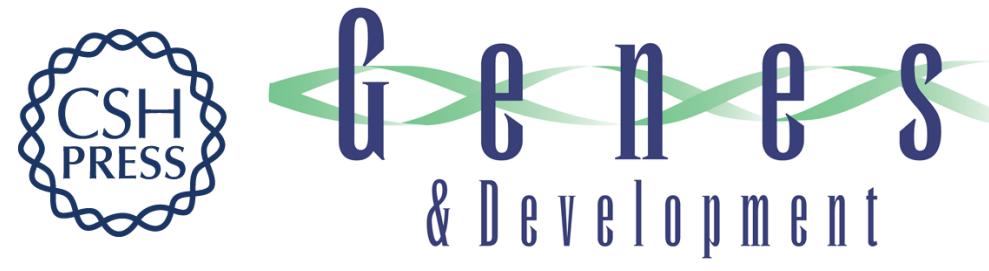

\section{MEK-2, a Caenorhabditis elegans MAP kinase kinase, functions in Ras-mediated vulval induction and other developmental events.}

Y Wu, M Han and K L Guan

Genes Dev. 1995, 9:

Access the most recent version at doi:10.1101/gad.9.6.742

References This article cites 51 articles, 18 of which can be accessed free at: http://genesdev.cshlp.org/content/9/6/742.full.html\#ref-list-1

License

Email Alerting

Service

Receive free email alerts when new articles cite this article - sign up in the box at the top right corner of the article or click here.

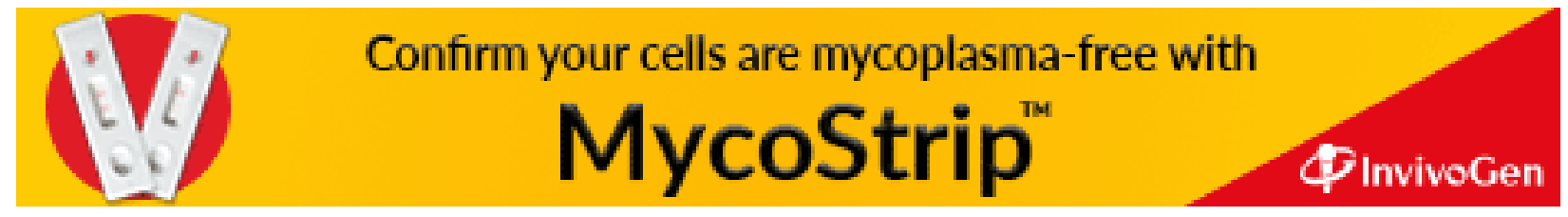

